\title{
miR-421 promotes the viability of A549 lung cancer cells by targeting forkhead box 01
}

\author{
XIAO-MEI MO ${ }^{1}$, PENG-FEI QIN ${ }^{1}$, BING WANG ${ }^{1}$, FENG-HAI LIU ${ }^{2}$ and HUA-HUI LI ${ }^{2}$ \\ ${ }^{1}$ Pharmacy Department, Qingdao Women and Children's Hospital, Qingdao University, Qingdao, Shandong 266034; \\ ${ }^{2}$ Department of Laboratory Medicine, Qingdao Municipal Hospital, Qingdao, Shandong 266071, P.R. China
}

Received December 6, 2019; Accepted July 16, 2020

DOI: 10.3892/ol.2020.12169

\begin{abstract}
MicroRNA (miR)-421 has been reported to serve various important roles in numerous types of cancer, including neuroblastoma and gastric cancer. However, to the best of our knowledge, few reports have determined the role of miR-421 in lung cancer. The aim of the current study was to analyze the expression levels of miR-421 in A549 lung cancer cells, to determine the target gene of miR-421, and to investigate the function and mechanism of miR-421 in cellular cytotoxicity. miR-421 expression levels were analyzed in A549 lung cancer cells using reverse transcription-quantitative PCR, a MTT assay was performed to determine the effect of miR-421 on A549 cell cytotoxicity and the protein expression levels of forkhead box O1 (FOXO1) were determined via western blotting. The target gene of miR-421 was predicted and verified using TargetScan and a dual-luciferase reporter assay, respectively. The results revealed that miR-421 expression levels were significantly upregulated in A549 lung cancer cell lines compared with the normal cells $(\mathrm{P}<0.01)$. Additionally, it was discovered that miR-421 promoted A549 cell viability $(\mathrm{P}<0.01)$ compared with A549 transfected with negative control. miR-421 was also identified to bind to the 3'-untranslated region of FOXO1. In A549 cells transfected with miR-421-mimics, the expression levels of phosphorylated (p)-AKT, p-glycogen synthase kinase-3 $\beta$, p-retinoblastoma and cyclin D1 were significantly upregulated $(\mathrm{P}<0.01)$, whereas the expression levels of FOXO1 and p21 were significantly downregulated $(\mathrm{P}<0.01)$ compared with the control group. In conclusion, the results of the present study suggested that miR-421 may promote the viability of A549 lung cancer cells by targeting FOXO1 and modulating cell cycle, indicating that targeting miR-421 and FOXO1 may represent future therapeutic strategies for the treatment of patients with lung cancer.
\end{abstract}

Correspondence to: Dr Hua-Hui Li or Dr Feng-Hai Liu, Department of Laboratory Medicine, Qingdao Municipal Hospital, 5 Donghai Zhong Road, Qingdao, Shandong 266071, P.R. China E-mail:1hh39153@163.com

E-mail: 1fhey@163.com

Key words: microRNA-421, lung cancer, viability, forkhead box O1

\section{Introduction}

Lung cancer is the leading cause of cancer-associated mortality worldwide (1), accounting for more deaths than breast, prostate and colon cancer combined (2-4). Although numerous studies have investigated the role of microRNAs (miRNAs/miRs) in patients with lung cancer, there has been relatively little progress in developing novel therapeutic strategies (5-8).

miRNAs are 20-22 nucleotides in length and serve as negative regulators of gene expression by binding to the complementary 3'-untranslated regions (UTRs) of their target genes (9). Previous studies have revealed that miRNAs participate in specific biological processes, including the cell cycle, aging and death $(10,11)$, and serve as hallmarks of several pathological conditions, including neoplasms $(12,13)$. It has been hypothesized that miRNAs may serve critical roles in the progression of cancer, cancer metastasis, angiogenesis (14) and drug resistance (15).

Numerous studies have revealed that miR-421 may be associated with several types of cancer, including neuroblastoma (16) and gastric cancer $(17,18)$. It has been revealed that miR-421 enhanced the proliferation and metastasis of gastric cancer cells by targeting claudin-11 (19). In addition, miR-421 induced cisplatin resistance by targeting E-cadherin and caspase-3 (20), and miR-421 promoted breast cancer progression by inhibiting caspase-10 (21). In lung cancer, miRNA sequencing revealed that the expression levels of various miRNAs were aberrantly upregulated, including miR-421 (22); however, the effect and mechanism of miR-421 in lung cancer cells remains unclear.

Several signaling pathways have important roles in cancer; for example, the AKT/glycogen synthase kinase (GSK)-3 $\beta$ pathway was discovered to regulate tumor cell proliferation and apoptosis (23). Upon activation of this pathway, various downstream molecules associated with the cell cycle, including forkhead box $\mathrm{O} 1$ (FOXO1), p21, retinoblastoma (Rb) and cyclin $\mathrm{D}$, are regulated, resulting in cell proliferation $(24,25)$. As a member of the FOX family, FOXO1 is a transcription factor that has been reported to serve a role in apoptosis and cancer development (26). FOXO1 has also been suggested to serve important roles in cell cycle regulation, apoptosis, proliferation and immune responses in various types of cancer (27).

The current study aimed to determine whether miR-421 modulated the viability of lung cancer cells by targeting 
FOXO1 and various other downstream molecules. The expression levels of miR-421 were analyzed in seven different lung cancer cell lines, the target gene of miR-421 was identified and verified, and the effect of miR-421 on the viability of lung cancer cells was determined. In addition, the potential mechanisms of action were investigated. The results of the current study may provide novel insights into the role of miR-421 in lung cancer and its possible molecular mechanisms.

\section{Materials and methods}

Cell lines and reagents. Seven lung cancer cell lines (A549; hLAMP,cat.no.XY-XB-2164; Calu-3; NCI-H1975; NCI-H1299; NCI-H1650; and NCI-H460) and human bronchial epithelial cell line (BEAS-2B) were purchased from Shanghai Oulu Biological Technology Co., Ltd. Moloney murine leukemia virus reverse transcriptase (MMLV-RT) was obtained from Toyobo Life Science. Anti-FOXO1 (cat. no. ab52874) was purchased from Abcam. The following primary antibodies were purchased from Santa Cruz Biotechnology, Inc.: anti-p21 (cat. no. sc-6246), anti-phosphorylated (p)-AKT (cat. no. sc-81433), anti-p-GSK-3 $\beta$ (cat. no. sc-81496), anti-p-Rb (cat. no. sc-377528), anti-cyclin D1 (cat. no. sc-8396), anti-Rb (cat. no. sc-102), anti-AKT (cat. no. sc-81434), anti-GSK3 $\beta$ (cat. no. sc-81462) and anti- $\beta$-actin (cat. no. sc-81178). The horseradish peroxidase (HRP)-conjugated rabbit anti-mouse antibody (cat.no sc-358914) was also purchased from Santa Cruz Biotechnology, Inc. LightSwitch ${ }^{\mathrm{TM}}$ luciferase assay reagents were obtained from Promega Corporation. miR-421-mimics, miR-421-inhibitors and their negative controls (NCs) were purchased from Guangzhou RiboBio Co., Ltd.

Reverse transcription-quantitative PCR (RT-qPCR). Total RNA was extracted from A549, hLAMP, Calu-3, NCI-H1975, NCI-H1299, NCI-H1650, NCI-H460 and BEAS-2B cells using TRIzol ${ }^{\circledR}$ reagent (Invitrogen; Thermo Fisher Scientific, Inc.). Total RNA was reverse transcribed into cDNA using MMLV-RT at $42^{\circ} \mathrm{C}$ for 50 min. qPCR was subsequently performed to detect the expression levels of miR-421 and SYBR Green I was provided by Thermo Fisher Scientific, Inc. [Mo, 2014 \#10303]. Each PCR cycle involved denaturation $\left(95^{\circ} \mathrm{C}, 30 \mathrm{sec}\right)$, annealing $\left(60^{\circ} \mathrm{C}, 30 \mathrm{sec}\right)$ and extension $\left(72^{\circ} \mathrm{C}\right.$, $30 \mathrm{sec}$ ) for 40 cycles. The specific primers for miR-421 and small nuclear RNA U6 were designed by Guangzhou RiboBio Co. Ltd. as follows: miR-421, forward 5'-GGCCGCGATCAA CAGACAT-3', reverse 5'-CCAGTGCAGGGTCCGAGGTA-3'; and small nuclear RNA U6, forward 5'-TGGCACCCAGCA CAATGA A-3' and reverse 5'-CTAAGTCATAGTCCGCCT AGAAGCA-3'. Expression levels were quantified using the $2^{-\Delta \Delta C q}$ method (28). Small nuclear RNA U6 was used as the loading control and for normalization.

Bioinformatics analysis. The target gene of miR-421 was predicted using TargetScan 7.2 software (http://www. targetscan.org/vert_72; Whitehead Institute for Biomedical Research).

Cell transfection. A549 cells $\left(3 \times 10^{5}\right)$ were transfected with $100 \mathrm{nmol}$ miR-421-mimics, miR-421-inhibitors or their NCs (Guangzhou RiboBio Co., Ltd.) using Lipofectamine ${ }^{\circledR} 2000$
(Invitrogen; Thermo Fisher Scientific, Inc.), according to the manufacturer's protocol. After $48 \mathrm{~h}$, transfected cells were subsequently used for the MTT assay and western blotting.

Luciferase reporter assay. The miR-421-mimics-NC, miR-421-mimics, miR-421-mutant (mut, synthesized by Guangzhou RiboBio Co., Ltd) or miR-421-inhibitor were co-transfected at $37^{\circ} \mathrm{C}$ using Lipofectamine 2000 into $5 \times 10^{5}$ A549 cells with the FOXO1-3'-UTR (inserted into the pGL3-control luciferase reporter plasmid; Promega Corporation) for $24 \mathrm{~h}$. Luciferase assays were performed using the LightSwitch ${ }^{\mathrm{TM}}$ reagents according to the manufacturer's protocol. The relative firefly and Renilla luciferase activities were determined using a luminometer (Promega Corporation). The relative luciferase activity was calculated as relative light units (Renilla luciferase/firefly luciferase) to determine whether FOXO1 was a target gene of miR-421.

MTT assay. Following transfection, A549 cells $\left(1 \times 10^{4}\right)$ were cultured at $37^{\circ} \mathrm{C}$ in 96 -well plates. After 1, 2,3,4 and 5 days of incubation, an MTT assay was performed to detect the viability of A549 cells as described by van Tonder et al (29). Briefly, following the incubation, $20 \mu \mathrm{l}$ MTT solution $(5 \mathrm{mg} / \mathrm{ml})$ was added to each well and incubated at $37^{\circ} \mathrm{C}$ for $4 \mathrm{~h}$. The medium was subsequently aspirated and $150 \mu \mathrm{l}$ DMSO was added to each well. The plates were placed on a shaker for $10 \mathrm{~min}$ and the absorbance was then determined at $570 \mathrm{~nm}$ using a reference wavelength of $630 \mathrm{~nm}$ on a microplate reader (Thermo Fisher Scientific, Inc.).

Colony formation assay. A549 cells transfected with miR-421-mimics or miR-421 mimics-NC were digested into single cells using $0.25 \%$ trypsin and plated at a density of 200 cells/well into 6-well-culture plates, which were incubated with $5 \% \mathrm{CO}_{2}$ at $37^{\circ} \mathrm{C}$ for 7-14 days. When a colony was observed, the supernatant was discarded and the cell culture was terminated. Subsequently, samples were washed three times with PBS and fixed with $1 \mathrm{ml} \mathrm{4 \%}$ methanol for $10 \mathrm{~min}$ at room temperature. The colonies were subsequently stained with $0.1 \%$ hematin for $10 \mathrm{~min}$ at room temperature and washed with distilled water. Colonies including $>50$ cells were counted under a microscope (IX71; Olympus Corporation).

Western blotting. The expression levels of FOXO1, AKT, p-AKT, GSK- $3 \beta, \mathrm{p}-\mathrm{GSK}-3 \beta, \mathrm{p} 21, \mathrm{Rb}, \mathrm{p}-\mathrm{Rb}$ and cyclin D1 in transfected cells were analyzed using western blotting. Briefly, total protein was extracted from cells using RIPA lysis buffer (Sigma-Aldrich; Merck KGaA). Total protein was quantified using a bicinchoninic acid protein assay kit and $20 \mu \mathrm{g}$ protein/lane was separated via $12 \%$ SDS-PAGE. The separated proteins were subsequently transferred onto PVDF membranes and blocked with 5\% skimmed milk at room temperature for $2 \mathrm{~h}$. The membranes were then incubated with the primary antibodies $(1: 3,000)$ at $4^{\circ} \mathrm{C}$ overnight. Following the primary antibody incubation, the membranes were incubated with the HRP-conjugated secondary antibody $(1: 6,000)$ at room temperature for $2 \mathrm{~h}$. Protein expression was quantitatively assessed using a HRP-ECL scanner (Lenovo, Beijing, People's Republic of China). 
Table I. MicroRNA-421 expression levels in lung cancer cell lines, as determined using reverse transcription-quantitative PCR.

\begin{tabular}{lc}
\hline Cell line & $2^{-\Delta \Delta C \mathrm{c}}$ value \\
\hline BEAS-2B & $1.00 \pm 0.00$ \\
A549 & $11.19 \pm 0.85^{\mathrm{a}}$ \\
hLAMP & $15.38 \pm 1.24^{\mathrm{a}}$ \\
Calu-3 & $6.12 \pm 0.86^{\mathrm{a}}$ \\
NCl-H1975 & $5.57 \pm 0.12^{\mathrm{a}}$ \\
NCl-H1299 & $8.05 \pm 1.07^{\mathrm{a}}$ \\
NCl-H1650 & $16.41 \pm 2.97^{\mathrm{a}}$ \\
NCl-H460 & $15.44 \pm 0.94^{\mathrm{a}}$ \\
\hline
\end{tabular}

Data are presented as the mean \pm SD. ${ }^{\mathrm{a}} \mathrm{P}<0.01$ vs. BEAS- $2 \mathrm{~B}$.

Table II. Verification of the miR-421 target gene FOXO1 using a luciferase reporter assay.

\begin{tabular}{lc}
\hline Group & RLuc/FLuc \\
\hline A549-miR-421-mimics-negative control & $1.00 \pm 0.00$ \\
A549-miR-421-mimics & $0.43 \pm 0.03^{\mathrm{a}}$ \\
A549- miR-421-inhibitor & $4.01 \pm 0.07^{\mathrm{a}}$ \\
A549-miR-421-mutant & $1.08 \pm 0.01$ \\
\hline
\end{tabular}

Data are presented as the mean \pm SD. ${ }^{\mathrm{a}} \mathrm{P}<0.01$ vs. A549-miR-421-mimics-NC. FOXO1, forkhead box O1; miR, microRNA; RLuc/FLuc, Renilla luciferase/firefly luciferase.

Statistical analysis. Statistical analysis was performed using SPSS 15.0 software (SPSS Inc.). Three independent experiments were performed and data were presented as the means \pm SD. An unpaired Student's t-test was used to determine the statistical differences between two groups, whereas a one-way ANOVA followed by Tukey's post hoc test was performed to determine statistical differences between $>2$ groups. $\mathrm{P}<0.05$ was considered to indicate a statistically significant difference.

\section{Results}

miR-421 expression levels are upregulated in lung cancer cell lines. Compared with the control cell line BEAS-2B, miR-421 expression levels were significantly upregulated in the lung cancer cell lines $(\mathrm{P}<0.01)$, particularly in A549 $(11.19 \pm 0.85)$, hLAMP $(15.38 \pm 1.24)$, NCI-H1650 $(16.41 \pm 2.97)$ and NCI-H460 $(15.44 \pm 0.94)$ cells (Table I). Among the aforementioned lung cancer cell lines, miR-421 expression levels in the A549 cells were neither the highest nor the lowest. For this reason, A549 cells were selected for further experimentation.

FOXO1 is a target gene of miR-421. The results of the bioinformatics analysis using TargetScan revealed a complementary binding site between miR-421 and the 3'-UTR of FOXO1 (Fig. 1). Thus, to verify the interaction between

\section{FOXO1-3'UTR 5' ${ }^{\prime}{ }_{2055}$ CAUUUUGGGGCAGUCCAAGACAU 2078 \\ miR-421 \\ miR-421-mut 3'ACGUACUGCCGGACGUUCUGU 5 3'ACGUACUGCCGGACGUCAGGU 5}

Figure 1. Predicted binding site between miR-421 and the 3'-UTR of FOXO1. Red indicates the mutated sequence of FOXO1 and blue indicates the complementary binding sequence of FOXO1 and miR-421. UTR, untranslated region; mut, mutant; FOXO1, forkhead box O1; miR, microRNA.

FOXO1 and miR-421, a luciferase assay was performed. Compared with the A549-miR-421-mimics-NC group, in the A549-miR-421-mimics group, the relative luciferase activity of the FOXO1 3'-UTR was significantly decreased $(1.00 \pm 0.00$ vs. $0.43 \pm 0.03$; $\mathrm{P}<0.01$; Fig. 2 ; Table II). Post-transfection with miR-421-mut, the relative luciferase activity of the FOXO1 3'-UTR remained at similar levels compared with the A549-miR-421-mimics-NC group (1.08 \pm 0.01 vs. $1.00 \pm 0.00$; $\mathrm{P}=0.71)$. Meanwhile, in the A549-miR-421-inhibitor group, the relative luciferase activity of the FOXO1 3'-UTR were significantly increased compared with in the A549-miR-421-mimics-NC group $(4.01 \pm 0.07$ vs. $1.00 \pm 0.00$; $\mathrm{P}<0.01)$. Thus, the results of the TargetScan analysis and luciferase reporter assay indicated that FOXO1 may be a target gene of miR-421.

miR-421 increases A549 cell viability. To determine whether transfection with the miR-421-mimics and inhibitor was successful, RT-qPCR was performed. In cells transfected with the miR-421-mimics, the expression levels of miR-421 were significantly upregulated compared with the A549-miR-421-mimics-NC group (13.37 \pm 1.21 vs. $1.00 \pm 0.00 ; \mathrm{P}<0.05$; Fig. 3). Conversely, in cells transfected with the miR-421-inhibitor, the expression levels of miR-421 were significantly downregulated compared with the A549-miR-421-inhibitors-NC group $(0.26 \pm 0.05$ vs. $1.03 \pm 0.03$; $\mathrm{P}<0.05$; Fig. 3)

The viability of the A549-miR-421-mimicsgroup was significantly increased compared with in the miR-421-mimics-NC group [optical density (OD) $)_{570} 5.72 \pm 0.02$ vs. $2.97 \pm 0.04$; $\mathrm{P}<0.01]$; Table III at $72 \mathrm{~h}$ post-transfection. By contrast, in the A549-miR-421-inhibitor group, cell viability was significantly decreased compared with in the A549-miR-421 inhibitor NC group $\left(\mathrm{OD}_{570} 1.64 \pm 0.01\right.$ vs. $\left.3.02 \pm 0.04 ; \mathrm{P}<0.01\right)$ at $72 \mathrm{~h}$.

Following transfection of A549 cells with the miR-421-mimics, the number of colonies formed was significantly increased compared with in the A549-miR-421mimics-NC group (113.96 \pm 7.22 vs. $44.07 \pm 5.10 ; \mathrm{P}<0.01$; Fig. 4).

miR-421 downregulates FOXO1 expression levels. To investigate whether miR-421 affected the expression levels of FOXO1, western blotting was performed. Compared with in the A549-miR-421-mimics-NC group, the expression levels of FOXO1 and p21 were downregulated, whereas the expression levels of p-AKT, p-GSK-3 $\beta, \mathrm{p}-\mathrm{Rb}$ and cyclin D1 were upregulated in the A549-miR-421-mimics group ( $\mathrm{P}<0.05$ Fig. 5). Compared with the A549-miR-421-inhibitor-NC group, the expression levels of FOXO1 and p21 were upregulated, whereas the expression levels of p-AKT, p-GSK-3 $\beta, \mathrm{p}-\mathrm{Rb}$ and cyclin D1 were downregulated in the A549-miR-421-mimics group $(\mathrm{P}<0.05$ Fig. 5). These results indicated that miR-421 
Table III. A549 cell viability following transfection with miR-421-mimics or miR-421-inhibitor.

\begin{tabular}{lcccc}
\hline Time, day & $\begin{array}{c}\text { A549-miR-421-mimics- } \\
\text { NC, OD }\end{array}$ & $\begin{array}{c}\text { A549-miR-421- } \\
\text { mimics, OD }\end{array}$ & $\begin{array}{c}\text { A549-miR-421- } \\
\text { inhibitor-NC, OD } 570\end{array}$ & $\begin{array}{c}\text { A549-miR-421- } \\
\text { inhibitor, OD }\end{array}$ \\
\hline 0 & $0.02 \pm 0.000$ & $0.03 \pm 0.00$ & $0.01 \pm 0.00$ & $0.03 \pm 0.00$ \\
1 & $1.39 \pm 0.004$ & $1.57 \pm 0.01^{\mathrm{a}}$ & $1.67 \pm 0.01$ & $1.11 \pm 0.01^{\mathrm{b}}$ \\
2 & $2.54 \pm 0.010$ & $3.94 \pm 0.04^{\mathrm{a}}$ & $2.09 \pm 0.01$ & $1.31 \pm 0.01^{\mathrm{b}}$ \\
3 & $2.97 \pm 0.040$ & $5.72 \pm 0.02^{\mathrm{a}}$ & $3.02 \pm 0.04$ & $1.64 \pm 0.01^{\mathrm{b}}$ \\
4 & $5.70 \pm 0.030$ & $10.81 \pm 0.01^{\mathrm{a}}$ & $5.94 \pm 0.15$ & $1.99 \pm 0.01^{\mathrm{b}}$ \\
5 & $8.10 \pm 0.030$ & $17.79 \pm 0.01^{\mathrm{a}}$ & $8.06 \pm 0.04$ & $4.98 \pm 0.02^{\mathrm{b}}$ \\
\hline
\end{tabular}

${ }^{\mathrm{a}} \mathrm{P}<0.01$ vs. A549-miR-421-mimics-NC; ${ }^{\mathrm{b}} \mathrm{P}<0.01$ vs. miR-inhibitor-NC. miR, microRNA; NC, negative control; OD, optical density.

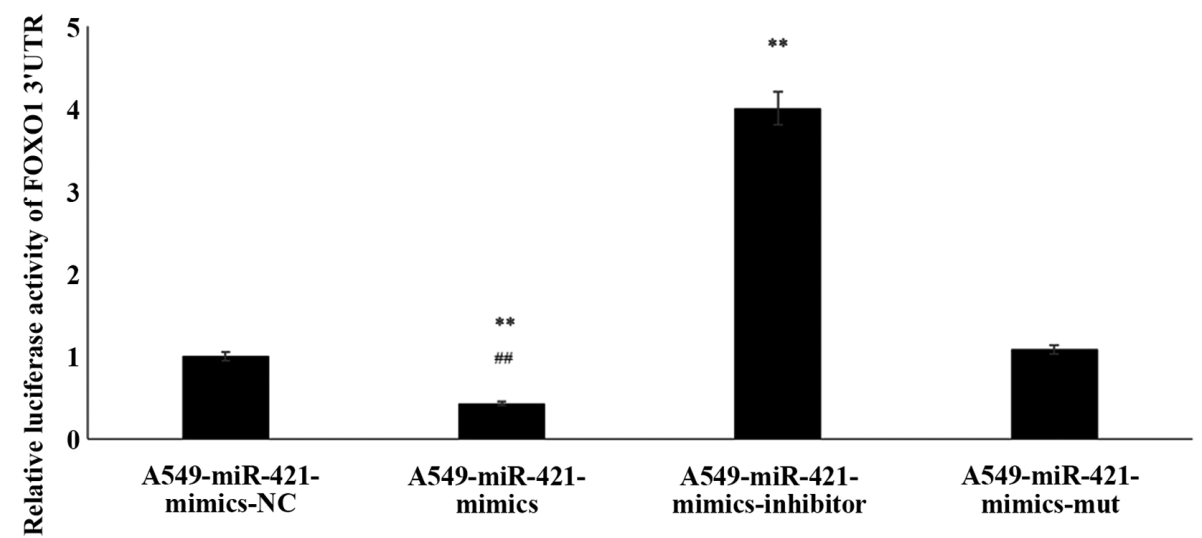

Figure 2. Verification of the miR-421 target geneFOXO1 using a luciferase reporter assay. Relative luciferase activity of the 3'-UTR of FOXO1 in A549 cells transfected with miR-421-mimics was decreased compared with the miR-421-mut and A549-miR-421-mimics-NC-transfected cells. ${ }^{* *} \mathrm{P}<0.01$ vs. A549-miR-421-mimics-NC. ${ }^{\# \#} \mathrm{P}<0.01$ vs. A549-miR-421-mut. FOXO1, forkhead box O1; miR, microRNA; UTR, untranslated region; mut, mutant; NC, negative control.

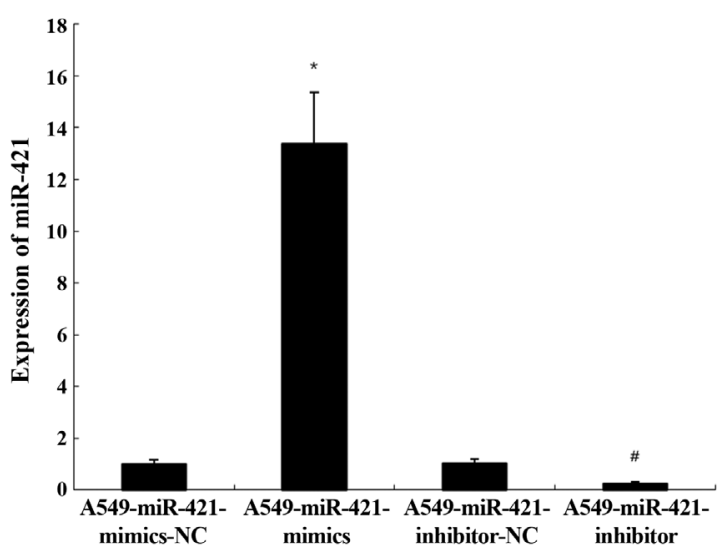

Figure 3. miR-421 expression levels in A549 cells transfected with miR-421 mimics and inhibitor. Following the transfection of A549 cells with miR-421-mimics, the expression levels of miR-421 were upregulated compared with in the A549-miR-421-mimics-NC group. Following the transfection of A549 cells with a miR-421-inhibitor, the expression levels of miR-421 were downregulated compared with in the A549-miR-421-inhibitor-NC group. The results were determined using reverse transcription-quantitative $\mathrm{PCR}$. ${ }^{*} \mathrm{P}<0.05$ vs. A549-miR-421-mimics-NC. " $\mathrm{P}<0.05$ vs. A549-miR-421-inhibitor-NC. miR, microRNA; NC, negative control.

may downregulate the expression levels of FOXO1 and p21, and upregulate $\mathrm{p}-\mathrm{AKT}$, $\mathrm{p}-\mathrm{GSK}-3 \beta, \mathrm{p}-\mathrm{Rb}$ and cyclin D1 expression levels in A549 cells.

\section{Discussion}

The present study demonstrated that miR-421 miR-421 promoted the viability of A549 lung cancer cells by targeting FOXO1. Previous studies reported that miR-421 is upregulated in neuroblastoma (16), gastric cancer $(17,18)$ and lung adenocarcinoma (22). The results from RT-qPCR analysis also revealed that the expression levels of miR-421 were significantly upregulated in the lung cancer cell lines, which is consistent with the results of above studies. In particular, in A549 cells, miR-421 expression levels were $\sim 11$-fold higher compared with in the control cell line BEAS-2B. Among the seven lung cancer cell lines analyzed, miR-421 expression levels in A549 cells were neither the highest nor the lowest; therefore, A549 cells were selected for further analysis. However, the role of mir-421 in lung cancer cell lines in not clear. In neuroblastoma, miR-421 substantially enhance cell proliferation, cell-cycle progression, migration and invasion of neuroblastoma cells through upregulation of P18 and P21 (16). Furthermore, miR-421 level is correlated with lymph node metastasis and prognosis of gastric carcinoma (17). miR-421 may therefore serve important roles in lung cancer cells by similar mechanisms.

Firstly, we studied the target gene of miR-421. TargetScan is a commonly used software for the prediction of miRNA target genes (30). The results of the present study revealed that FOXO1 may be a target gene of miR-421. Luciferase reporter 
A549-miR-421-mimics-NC A549-miR-421-mimics

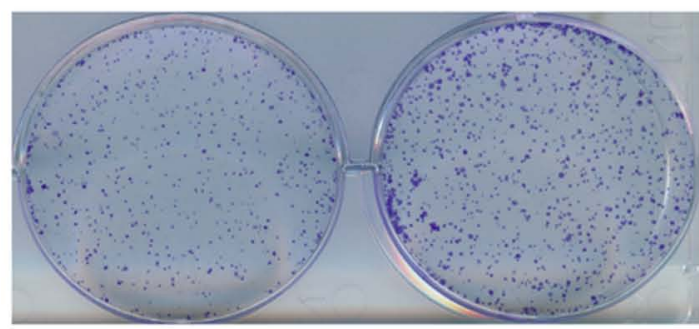

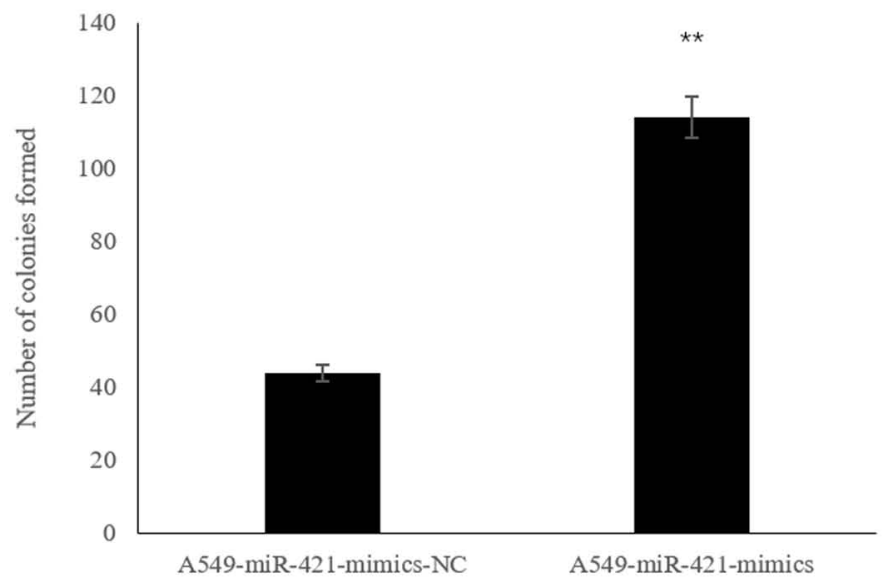

Figure 4. Colony formation rate of A549 cells transfected with the miR-421-mimic. Following the transfection of A549 cells with the miR-421-mimics, the number of colonies formed was increased compared with in the A549-miR-421-mimics-NC group. ${ }^{* *} \mathrm{P}<0.01$ vs. A549-miR-421-mimics-NC. miR, microRNA; $\mathrm{NC}$, negative control.

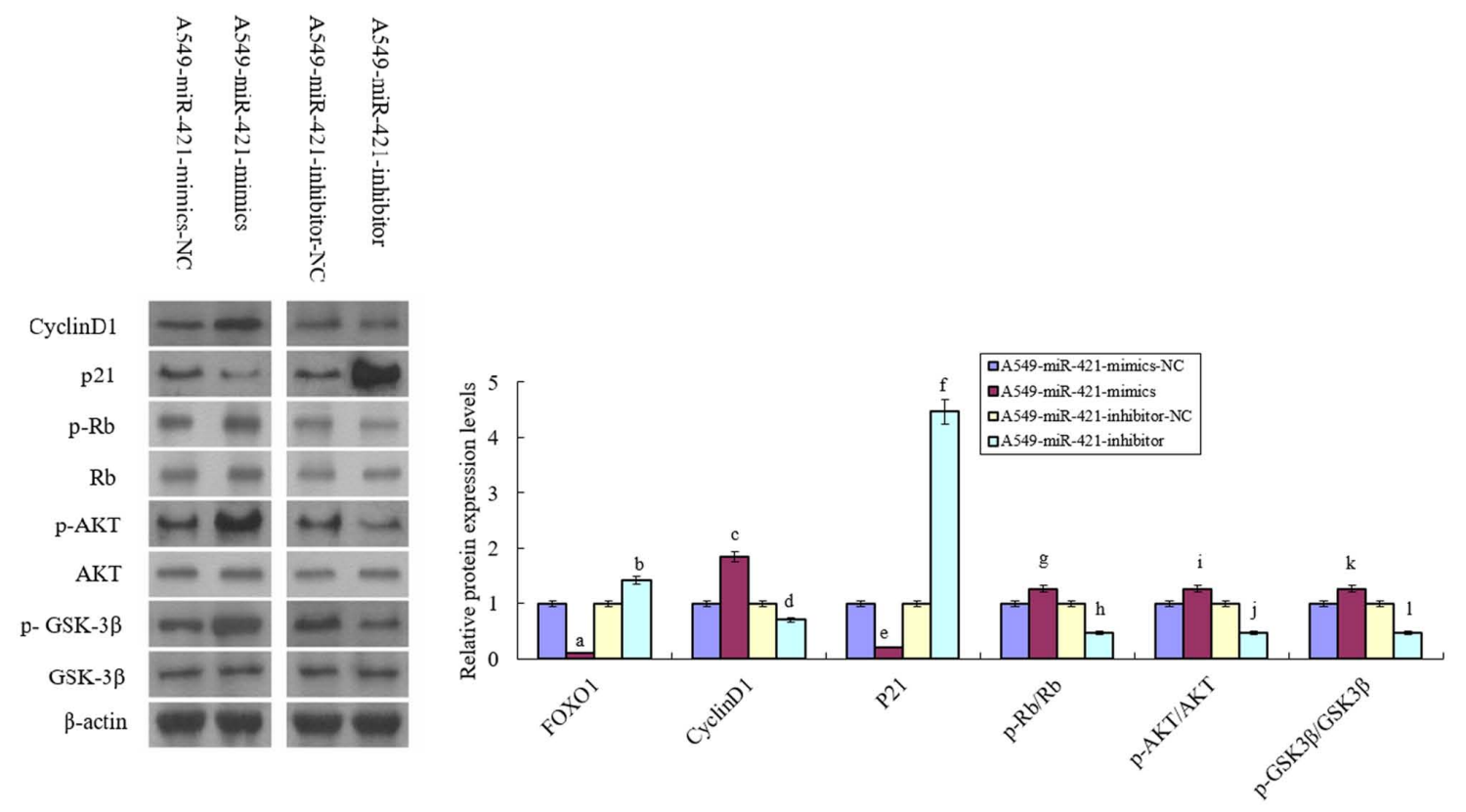

Figure 5. Western blot analysis of protein expression levels involved in the AKT/GSK-3 $\beta$ pathway. In A549 cells transfected with the miR-421-mimics, the expression levels of FOXO1 and p21 were downregulated, whereas the expression levels of cyclin D1 and the ratios p-AKT/AKT, p-GSK-3 $\beta / G S K-3 \beta$ and p-Rb/Rb were increased. For a, c, e, g, I and k:, P<0.05 vs. A549-miR-421-mimics-NC. For b, d, f, h, j and : P<0.05 vs. A549-miR-421-inhibitor-NC. miR, microRNA; NC, negative control; FOXO1, forkhead box O1; p-, phosphorylated; GSK-3 $\beta$, glycogen synthase kinase $3 \beta$; Rb, retinoblastoma.

assays are commonly performed to verify the results of TargetScan (31). In the present study, the results demonstrated that miR-421 bound to the 3'-UTR of FOXO1 and inhibited the expression of the reporter gene. Therefore, these findings indicated that FOXO1 may be a target gene of miR-421. The effect of miR-421 and its target gene, FOXO1, were further analyzed using A549 cells. Then, an MTT assay was subsequently performed to determine the effects of miR-421 on the viability of A549 cells. Post-transfection with the miR-421-mimics, the OD values across 5 days were increased compared with in the A549-miR-421-mimics-NC group. Finally, we studied the molecular mechanisms of miR-421 on the viability of A549 cells. The effect may be associated with the downregulated expression levels of FOXO1. In addition, p21, GSK-3 $\beta, \mathrm{p}-\mathrm{Rb}$ and cyclin D1 expression levels in A549 cells transfected with
miR-421-mimics were determined. The results revealed that the expression levels of FOXO1 and p21 were significantly downregulated, whereas the expression levels of p-AKT, p-GSK-3 $\beta$, $\mathrm{p}-\mathrm{Rb}$ and cyclin D1 were significantly upregulated by the miR-421 mimic. These proteins are downstream molecules of FOXO1 (23). The results from the present study indicated that AKT/GSK-3 $\beta$ pathway was activated, resulting in the change of p-AKT, p-GSK-3 $\beta, \mathrm{p}-\mathrm{Rb}$ and cyclin D1 protein expression. These proteins are strongly associated with cell cycle progression and apoptosis (32-34). Furthermore, the A549 cell cycle transitioned from $\mathrm{G}_{1}$ to $\mathrm{S}$ phase, which stimulates proliferation and inhibits apoptosis (35).

In conclusion, the current study provided novel evidence to suggest that upregulated expression levels of miR-421 may significantly suppress FOXO1 expression, resulting in the 
enhanced viability of A549 cells in vitro. The regulation of miR-421 via FOXO1 may provide novel insight into the pathophysiology of lung cancer and a potential therapeutic target for the treatment of patients with lung cancer.

\section{Acknowledgements}

The authors would like to thank Mr. Liu Ming (School of Medicine and Pharmacy, Ocean University of China, Qingdao, Shandong, China) for his help revising the manuscript.

\section{Funding}

No funding was received.

\section{Availability of data and materials}

The datasets used and/or analyzed during the present study are available from the corresponding author on reasonable request.

\section{Authors' contributions}

XM wrote the manuscript. XM, PQ, BW, FL and HL performed the experiments and analyzed the data. HL and FL designed the study. All authors read and approved the final manuscript.

\section{Ethics approval and consent to participate}

Not applicable.

\section{Patient consent for publication}

Not applicable.

\section{Competing interests}

The authors declare that they have no competing interests.

\section{References}

1. Zhou C, Zhu Y, Lu B, Zhao W and Zhao X: Survivin expression modulates the sensitivity of A549 lung cancer cells resistance to vincristine. Oncol Lett 16: 5466-5472, 2018.

2. Chen Z, Wang J, Bai Y, Wang S, Yin X, Xiang J, Li X, He M, Zhang X, Wu T, et al: The associations of TERT-CLPTM1L variants and TERT mRNA expression with the prognosis of early stage non-small cell lung cancer. Cancer Gene Ther 24: 20-27, 2017.

3. Joshi M, Ayoola A and Belani CP: Small-cell lung cancer: An update on targeted. Adv Exp Med Bio 779: 385-404, 2013.

4. Carter BW, Halpenny DF, Ginsberg MS, Papadimitrakopoulou VA and de Groot PM: Immunotherapy in non-small cell lung cancer treatment: Current status and the role of imaging. J Thorac Imaging 32: 300-312, 2017.

5. Li L, Sun Y, Feng M, Wang L and Liu J: Clinical significance of blood-based miRNAs as biomarkers of non-small cell lung cancer. Oncol Lett 15: 8915-8925, 2018.

6. Lu J, Zhan Y, Feng J, Luo J and Fan S: MicroRNAs associated with therapy of non-small cell lung cancer. Int J Biol Sc 14: 390-397, 2018.

7. Guarize J, Bianchi F, Marino E, Belloni E, Vecchi M, Donghi S Lo Iacono G, Casadio C, Cuttano R, Barberis M, et al: MicroRNA expression profile in primary lung cancer cells lines obtained by endobronchial ultrasound transbronchial needle aspiration. J Thorac Dis 10: 408-415, 2018.

8. Iqbal MA, Arora S, Prakasam G, Calin GA and Syed MA: MicroRNA in lung cancer: Role, mechanisms, pathways and therapeutic relevance. Mol Aspects Med 70: 3-20, 2019.
9. Seok H, Ham J, Jang ES and Chi SW: MicroRNA Target Recognition: Insights from Transcriptome-Wide Non-Canonical Interactions. Mol Cells 39: 375-381, 2016.

10. Isik M, Blackwell TK and Berezikov E: MicroRNA mir-34 provides robustness to environmental stress response via the DAF-16 network in C. elegans. Sci Rep 6: 36766, 2016.

11. Wojciechowska A, Braniewska A and Kozar-Kamińska K: MicroRNA in cardiovascular biology and disease. Adv Clin Exp Med 26: 865-874, 2017.

12. Tran N: Cancer Exosomes as miRNA Factories. Trends Cancer 2: 329-331, 2016.

13. Wang JK, Wang Z and Li G: MicroRNA-125 in immunity and cancer. Cancer Lett 454: 134-145, 2019.

14. Chen YL, Xu QP, Guo F and Guan WH: MicroRNA-302d downregulates TGFBR2 expression and promotes hepatocellular carcinoma growth and invasion. Exp Ther Med 13: 681-687, 2017.

15. An X, Sarmiento C, Tan T and Zhu H: Regulation of multidrug resistance by microRNAs in anti-cancer therapy. Acta Pharm Sin B 7: 38-51, 2017.

16. Li Y, Li W, Zhang JG, Li HY and Li YM: Downregulation of tumor suppressor menin by miR-421 promotes proliferation and migration of neuroblastoma. Tumour Biol 35: 10011-10017, 2014.

17. Liu H, Gao Y, Song D, Liu T and Feng Y: Correlation between microRNA-421 expression level and prognosis of gastric cancer. Int J Clin Exp Pathol 8: 15128-15132, 2015.

18. Wu J, Li G, Yao Y, Wang Z, Sun W and Wang J: MicroRNA-421 is a new potential diagnosis biomarker with higher sensitivity and specificity than carcinoembryonic antigen and cancer antigen 125 in gastric cancer. Biomarkers 20: 58-63, 2015.

19. Yang P, Zhang M, Liu X and Pu H: MicroRNA-421 promotes the proliferation and metastasis of gastric cancer cells by targeting claudin-11. Exp Ther Med 14: 2625-2632, 2017.

20. Ge X, Liu X, Lin F, Li P, Liu K, Geng R, Dai C, Lin Y, Tang W, Wu Z, et al: MicroRNA-421 regulated by HIF-1alpha promotes metastasis, inhibits apoptosis, and induces cisplatin resistance by targeting E-cadherin and caspase- 3 in gastric cancer. Oncotarget 7: 24466-24482, 2016.

21. Hu TB, Chen HS, Cao MQ, Guo FD, Cheng XY, Han ZB and Li MQ: MicroRNA-421 inhibits caspase-10 expression and promotes breast cancer progression. Neoplasma 65: 49-54, 2018.

22. Cinegaglia NC, Andrade SC, Tokar T, Pinheiro M, Severino FE, Oliveira RA, Hasimoto EN, Cataneo DC, Cataneo AJ, Defaveri J, et al: Integrative transcriptome analysis identifies deregulated microRNA-transcription factor networks in lung adenocarcinoma. Oncotarget 7: 28920-28934, 2016.

23. Chen Z, Yu W, Zhou Q, Zhang J, Jiang H, Hao D, Wang J, Zhou Z, He C and Xiao Z: A Novel lncRNA IHS promotes tumor proliferation and metastasis in HCC by Regulating the ERK- and AKT/GSK-3 $\beta$-Signaling Pathways. Mol Ther Nucleic Acids 16: 707-720, 2019.

24. Kim SA, Kang OH and Kwon DY: Cryptotanshinone Induces Cell Cycle Arrest and Apoptosis of NSCLC Cells through the PI3K/Akt/GSK-3 $\beta$ Pathway. Int J Mol Sci 19: 2739, 2018.

25. Chen Y, Liu X, Wang H, Liu S, Hu N and Li X: Akt regulated phosphorylation of GSK-3 $3 /$ Cyclin D1, p21 and p27 contributes to cell proliferation through cell cycle progression from G1 to S/G2M Phase in low-dose arsenite exposed HaCat cells. Front Pharmacol 10: 1176, 2019.

26. Coomans de Brachene A and Demoulin JB: FOXO transcription factors in cancer development and therapy. Cell Mol Life Sci 73: 1159-1172, 2016.

27. Chen D, Yang Y and Yang P: Quxie capsule inhibits colon tumor growth partially through foxol-mediated apoptosis and immune modulation. Integr Cancer Ther 18: 1534735419846377, 2019

28. Livak KJ and Schmittgen TD: Analysis of relative gene expression data using real-time quantitative PCR and the 2(-Delta Delta C(T)) method. Methods 25: 402-408, 2001.

29. van Tonder A, Joubert AM and Cromarty AD: Limitations of the 3-(4,5-dimethylthiazol-2-yl)-2,5-diphenyl-2H-tetrazolium bromide (MTT) assay when compared to three commonly used cell enumeration assays. BMC Res Notes 8: 47, 2015.

30. Riffo-Campos AL, Riquelme I and Brebi-Mieville P: Tools for sequence-based miRNA target prediction: What to choose? Int $\mathrm{J}$ Mol Sci 17: 1987, 2016.

31. Xie D, Shang C, Zhang H, Guo Y and Tong X: Up-regulation of miR-9 target CBX7 to regulate invasion ability of bladder transitional cell carcinoma. Med Sci Monit 21: 225-230, 2015. 
32. Zuryn A, Litwiniec A, Gagat M, Drzewucka J, Gackowska L and Grzanka A: The influence of arsenic trioxide on the cell cycle, apoptosis and expression of cyclin D1 in the Jurkat cell line. Acta Histochem 116: 1350-1358, 2014.

33. Gongpan P, Lu Y, Wang F, Xu Y and Xiong W: AS160 controls eukaryotic cell cycle and proliferation by regulating the CDK inhibitor p21. Cell cycle (Georgetown, Tex.) 15: 1733-1741, 2016.

34. Fukuda Y, Kanbe M, Watanabe M, Dan K, Matsuzaki K, Kitanaka S and Miyata S: 3EZ,20Ac-ingenol, a catalytic inhibitor of topoisomerases, downregulates p-Akt and induces DSBs and apoptosis of DT40 cells. Arch Pharm Res 36: 1029-1038, 2013.
35. Mao Z, Zhou J, Luan J, Sheng W, Shen X and Dong X: Tamoxifen reduces $\mathrm{P}$-gp-mediated multidrug resistance via inhibiting the PI3K/Akt signaling pathway in ER-negative human gastric cancer cells. Biomed Pharmacother 68: 179-183, 2014.

cc)(ㅇ) This work is licensed under a Creative Commons cc) International (CC BY-NC-ND 4.0) License. 